\title{
DESIGN AND IMPLEMENTATION OF CONVEYOR LINE SPEED SYNCHRONISER FOR INDUSTRIAL CONTROL APPLICATIONS: A CASE STUDY OF CHAMPION'S BREWERIES PLC, UYO
}

\author{
M. A. Umoren ${ }^{1}$, A. O. Essien ${ }^{2}$ and I. I. Ekpoudom ${ }^{3}$ \\ 1,2,3 Dept. of Electrical/Electronics \& Computer EngineERing, Uni. of Uyo, Uyo. AKWA Ibom State. NiGERIA \\ E-mail addresses:1mfon4gigis@yahoo.com, 2ani4good@yahoo.com,33ighpointer7@yahoo.com
}

\begin{abstract}
This paper presents the mathematical modeling of a conveyor mechanism for control applications with Champion Breweries PLC as a case study. The electrical and mechanical sections were modeled separately and then integrated to obtain one composite system. Due to the lack of synchronisation of the conveyor line speed and the speed of action of the empty bottle inspection (EBI), and the full bottle inspection (FBI) units at Champion Breweries, there exists the problem of residue left-over in bottles, cracked bottles on the conveyor line and the non-detection of incorrect liquor level in bottles. Therefore a Proportional Integral Derivative(PID) controller was designed to act as a speed synchronizer in order to eliminate the above mentioned problems.
\end{abstract}

\section{Keywords: Conveyor belt, DC motor, PID Controller, Speed Synchroniser, Laplace transform}

\section{INTRODUCTION}

A conveyor is a mechanical system that is often spread out over a considerable distance. These are used to move either bulk materials or unit items through the manufacturing process, and are available in various types of industrial plant. Conveyor applications involve an elementary speed control strategy in which the drive simply regulates the operating speed at a set point that may be adjusted from time to time [1].

Conveyor lines speed synchronisers are essential and indispensable components of any industrial production lines. The reason for this device is to synchronise the conveyor lines speed with the speed of action of all the process machines within the production network [2]. This is achieved by the ability of the synchroniser to properly adjust and allocate an appropriate voltage to the drive systems of the conveyor at every point in time during production, by accurately tracking the reference signal and rejecting disturbances in the system.A lack of synchronization of the conveyor line speed and the speed of action of other process machines results in various problems. In order to design controllers for the system to tackle the problems, it is necessary to develop a model of the system.

\section{METHODOLOGY}

\subsection{Design of DC Motor and Belt Conveyor System}

In order to describe the dynamic behavior of the conveyor lines speed synchronizer, a model of the motor drive-conveyor system needs to be derived mathematically [3]. First, the model of a single line belt conveyor system driven by a DC motor is considered for the case of Champion Breweries, Uyo. The design set out to use a simple DC motor for driving the inertial load of the belt conveyor as shown in Figure 1. The input of the system is applied voltage $\left(V_{a p p}\right)$ to the electrical circuit of the motor and the output is the angular speed $(\omega(t))$ of the motor shaft, directly coupled to the drive pulley or roller of the belt conveyor [4]. In Figure $1, R$ is the resistance of motor circuit, $L$ is the self-inductance of motor armature, $\tau$ is the torque produced at the shaft of the motor, $V_{\text {emf }}$ is the back induced electromotive force, $J_{\text {conv }}$ is the total inertia of the belt conveyor, $J_{R}$ is the inertia of the motor rotor and $\mathrm{K}_{\mathrm{f}} \omega(\mathrm{t})$ is the viscous friction. The parameters shown in Figure 1 are:

\subsection{Electrical Aspects}

The electrical circuit has a voltage source $\left(V_{a p p}\right)$ across the coil of the armature. The armature coil is 
described by an inductance $(L)$ in series with a resistance $(R)$ in series with induced voltage $V_{e m f}$ which opposes the voltage source [8]. A differential equation for the equivalent circuit can be derived using Kirchoff's voltage law around the electrical loop. Kirchoff put forth that the sum of all voltages around a loop is zero [9].

$$
V_{a p p}-V_{R a}-V_{L a}-V_{e m f}=0
$$

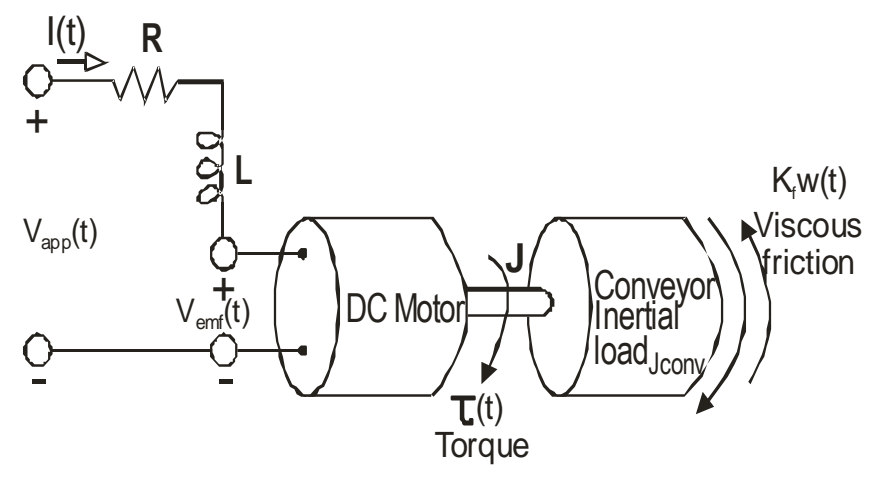

Figure 1: Schematic diagram of the DC Motor and Belt Conveyor system [18].

The voltage across the resistor is represented below with Ohm's law being applied

$$
V_{R a}=R i(t)
$$

where $i(t)$ is the armature current. The inductor has a voltage across the terminal and this is proportional to the change of current through the coil with respect to time [5].

$$
V_{L a}=\frac{\operatorname{Ldi}(t)}{d t}
$$

Finally, the back induced emfcan be written as

$$
V_{\text {emf }}=K_{b} \omega(t)
$$

where $K_{b}$ is the velocity constant determined by the flux density of the permanent magnets, the reluctance of the iron core of the armature, and the number of turns of the armature windings [2].

Substituting equations (2), (3) and (4) into equation (1) yields the following differential equation:

$$
V_{a p p}(t)-R i(t)-\frac{L d i(t)}{d t}-K_{b} \omega(t)=0
$$

Solving for the applied voltage,

$$
V_{a p p}(t)=R i(t)+\frac{L d i(t)}{d t}+K_{b} \omega(t)
$$

\subsection{Mechanical Aspects}

Conveyors are constant torque machines [2]. That means a constant level of torque is required to drive the conveyor regardless of the operating speed [11]. The mechanical part of the motor equation is derived using Newton's law which states that the inertial load times the derivative of angular rate equals the sum of all the torques about the motor shaft. By energy conservation, the resultant torque on motor shaft must equal zero.

$$
\tau(t)-T_{\omega}^{\prime}-T_{\omega}-T_{c}=0
$$

Where $\tau(t)$ is the electromagnetic torque, $T_{\omega}^{\prime}$ is the torque due to rotational acceleration of the rotor, $T_{\omega}$ is torque associated with velocity of rotor, and $T_{c}$ is the torque of the belt conveyor system [7]. The electromagnetic torque is proportional to the current through the armature winding and is written as:

$$
\tau(t)=K_{m} i(t)
$$

where $K_{m}$ is torque constant and is dependent on flux density of the fixed magnets, the reluctance of the iron core, and the number of turns in the armature windings. $T_{\omega}^{\prime}$ is written as

$$
T_{\omega}^{\prime}=\frac{J_{t o t} d \omega(t)}{d t}
$$

Where $J_{\text {tot }}$ is the inertia of the rotor and the conveyor system. The torque produced as a result of rotor velocity is written as:

$$
T_{\omega}=K_{f} \omega(t)
$$

Where $K_{f}$ is the damping coefficient or viscous friction associated with the rotating members of the motor [12].

Substituting equations (8), (9) and (10) into (7) results in the following expression:

$$
K_{m} i(t)-\frac{J d \omega(t)}{d t}-K_{f} \omega(t)-T_{c}
$$

This sequence of equations leads to a set of two differential equations, the first for the induced current (equation 12) and the second for the resulting angular rate (equation 13).

$$
\begin{aligned}
& \frac{d i(t)}{d t}=-\frac{R}{L} i(t)-\frac{K_{b}}{L} \omega(t)+\frac{1}{L} V_{a p p}(t) \\
& \frac{d i(t)}{d t}=-L^{-1}\left[R i(t)+K_{b} \omega(t)-V_{a p p}(t)\right] \\
& \frac{d \omega(t)}{d t}=\frac{K_{m}}{J_{t o t}} i(t)-\frac{K_{f}}{J_{t o t}} \omega(t)+\frac{T_{c}}{J_{t o t}} \\
& \frac{d \omega(t)}{d t}=J_{t o t}^{-1}\left[K_{m} i(t)-K_{f} \omega(t)+T_{c}\right]
\end{aligned}
$$

\subsection{Design of Belt Conveyor Torque $\boldsymbol{T}_{c}$}

From equations (14) and (15), one needs to explicitly derive the torque, $T_{c}$ of the entire conveyor system in order to characterize the motor lead requirements. In this design, the conveyor is assumed to be coupled directly to the motor pulley or roller, where $M_{1}, M_{2}$, $\mathrm{M}_{3}$ are mass of bottles, $M_{\text {belt }}$ is mass of belt, $D_{m}$ is the diameter of motor pulley, $D_{1}$ is the diameter of driven pulley and $D_{i}$ is the diameter of idler, $J_{m}$ is mass inertia of shaft and all rotating components about 
shaft $1, J_{r}$ is the idler mass inertia and $J_{1}$ is the inertia of the driven pulley and shaft 2 (refer to Figure 2).

The total amount of mass being transported by the conveyors system involves mass of individual bottles in addition to mass of belt.

$$
M_{T}=M_{1}+M_{2}+M_{3}+M_{\text {belt }}
$$

Applying Newton's second law, $\mathrm{M}_{\mathrm{T}}$ can be related to the force necessary to accelerate it.

$$
F_{e}=M_{T} a
$$

In (17), $F_{e}$ is the effective belt tension and $a$ is the linear acceleration of the conveyor belt. In terms of angular measures, the linear acceleration can be expressed as

$$
F_{e}=\frac{1}{2} D_{m} M_{T} \alpha_{m}
$$

Where $\alpha_{m}$ is the angular acceleration of the conveyor drive pulley coupled to the motor shaft [10].

The force necessary to accelerate $\mathrm{M}_{\mathrm{T}}$ is related to the torque about the motor shaft as follows:

$$
\begin{array}{r}
\tau_{M_{T}}=\frac{1}{4} M_{T} D_{m}^{2} \alpha_{m} \\
J_{M_{T}}=\frac{1}{4} M_{T} D_{m}^{2}\left[\frac{D_{m}}{D_{1}}\right]^{2}
\end{array}
$$

Equation (19) is the torque which must be included in the analysis of the drive requirement of the conveyor system. Transforming all motion effects relating to torque to the motor shaft, determine the mass moment of inertia of all components undergoing rotational motion and reflect to drive shaft of conveyor system using scale factor consistent with reflected impedances [9].

Reflected impedance scale factor $\mathrm{L}$ is given by:

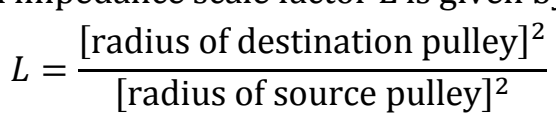

$$
l=\left[\frac{D_{m}}{D_{1}}\right]^{2}
$$

Considering the drive pulley and shaft 1 , the mass inertia of all rotating component is written as:

$$
J_{m R}=J_{m}\left[\frac{D_{m}}{D_{1}}\right]^{2}
$$

Considering the driven pulley and shaft 2 , the reflected mass inertia to shaft 1 is as follows:

$$
J_{1 R}=J_{1}\left[\frac{D_{m}}{D_{1}}\right]^{2}
$$

For the idlers, the mass moment of inertia reflected to shaft 1 is

$$
J_{r R}=n J_{r}\left[\frac{D_{m}}{D_{i}}\right]^{2}
$$

Wheren is the number of idler along the conveyor length $\left(L_{c}\right)$.

Consider the motion of the belt which creates friction between pulleys, idlers and the belt itself. If the pulleys and idlers surface is approximated by a platform, the magnitude of the friction force is related to the normal force and the coefficient of friction existing between the belt and the platform as follows:

$$
F_{f}=\mu N
$$

In (25), $\mu$ is the coefficient of friction between conveyor belt and platform and $N$ is the normal force acting to press the belt against the platform [14]. To relate the friction force $F_{f}$ to the torque requirement for motor of the conveyor system, $F_{f}$ can be related to the torque acting about the motor shaft as written below:

$$
\begin{aligned}
& T_{f}=\frac{1}{2} F_{f} D_{m}=\frac{1}{2} \mu N D_{m} \\
& T_{f}=\frac{1}{2} \mu M_{T} g D_{m}
\end{aligned}
$$

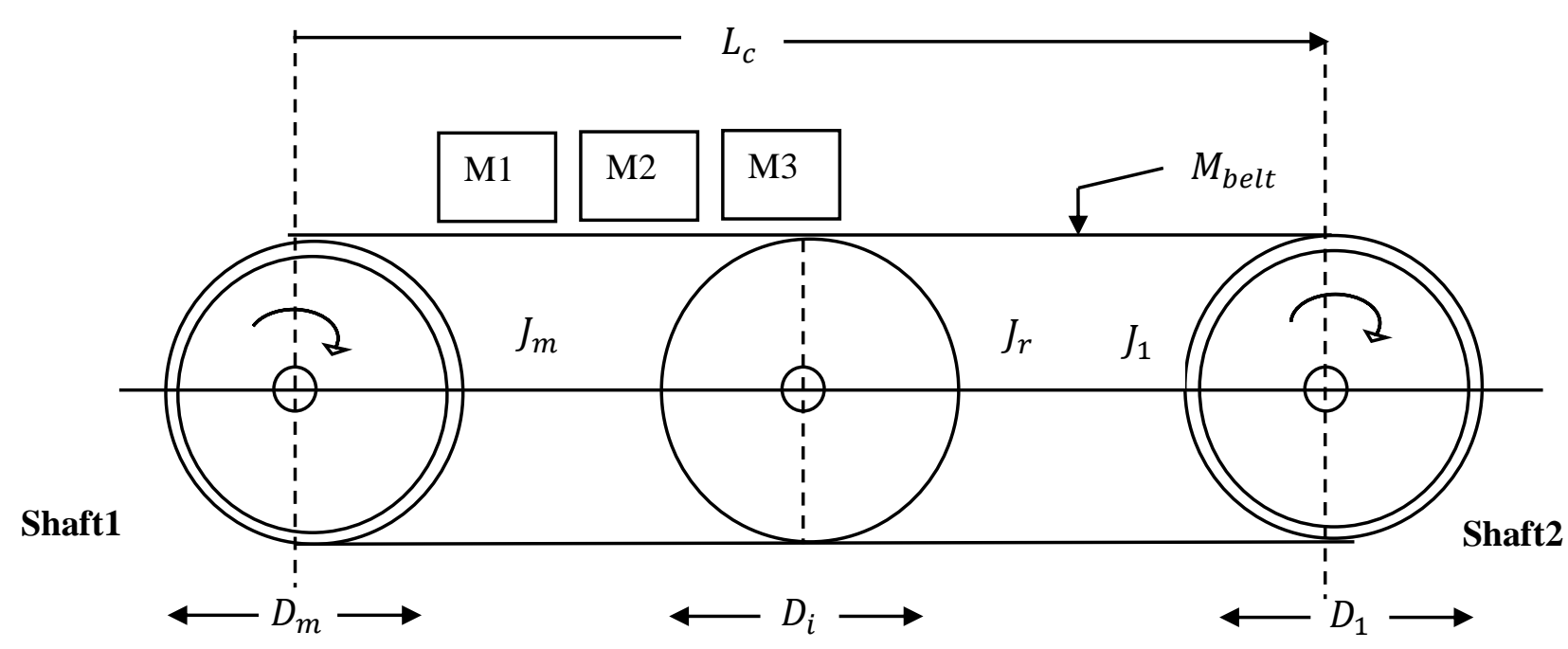

Figure 2: Schematic drawing of the belt conveyor for DC motor torque analysis 
Combining equations (19), (22), (23) and (24) the total mass inertia about the drive shaft1 is written as:

$$
\begin{gathered}
J_{\text {conv }}=J_{m R}+J_{1 R}+J_{r R}+J_{M_{T}} \\
J_{\text {conv }}=J_{m}\left[\frac{D_{m}}{D_{1}}\right]^{2}+J_{1}\left[\frac{D_{m}}{D_{1}}\right]^{2}+n J_{r}\left[\frac{D_{m}}{D_{i}}\right]^{2} \\
+\frac{1}{4} M_{T} D_{m}^{2}\left[\frac{D_{m}}{D_{1}}\right]^{2} \\
J_{c o n v}=\left[\frac{D_{m}}{D_{1}}\right]^{2}\left(J_{m}+J_{1}+n J_{r}\left[\frac{D_{1}}{D_{i}}\right]^{2}+\frac{1}{4} M_{T} D_{m}^{2}\right)
\end{gathered}
$$

Recall that Newton's second law for angular motion relating torque, mass inertia, and acceleration is given by: ${ }^{T}=J \alpha$

And for the conveyor belt drive,

$$
T=J_{\text {conv }} \alpha_{m}
$$

Therefore, the total torque produced by the belt conveyor system is written as follows by combining equations 23, 24 and 25.

$$
\begin{aligned}
T_{c}=\left(J_{m}+J_{1}+\right. & \left.n J_{r}\left[\frac{D_{1}}{D_{i}}\right]^{2}+\frac{1}{4} M_{T} D_{m}^{2}\right)\left(\frac{D_{m}}{D_{1}}\right)^{2} \alpha_{m} \\
& +\frac{1}{2} \mu M_{T} g D_{m}
\end{aligned}
$$

From equation (15),

$$
J_{\text {tot }}=J_{R}+J_{\text {conv }}
$$

Note that the mass inertia of any solid shaft or cylinder is written as

$$
J_{m s}=\frac{1}{2} M_{T} R^{2}=\frac{1}{2} \rho \pi l R^{4}
$$

There is need to compute the torque and inertia requirement of the motor. Assuming the materials of all pulleys and idlers are made of aluminum with their length equal to the width of the belt [15]. Then the governing differential equation for the motor and conveyor belt is written as:

$$
\begin{gathered}
\frac{d i(t)}{d t}=-L^{-1}\left[\operatorname{Ri}(t)+K_{b} \omega(t)-V_{a p p}(t)\right] \\
\frac{d \omega(t)}{d t}=J_{\text {tot }}^{-1}\left[K_{m} i(t)-K_{f} \omega(t)+T_{c}\right]
\end{gathered}
$$

Where $T_{c}$ is given by equation (32).

The inertias and torque requirement of the system are calculated using equations (30), (32) and (27).

$$
J_{\text {conv }}=1.760 \mathrm{kgm}^{2}
$$

Therefore,

$$
T_{c}=\left(1.7607 \alpha_{m}+9.6825\right) N m
$$

In (38), $\alpha_{m}$ is angular acceleration of drive drum or motor pulley. $J_{\text {tot }}=J_{\text {conv }}+J_{R}$ or $J_{\text {tot }}=1.7607+$ $1.8 \times 10^{-2}=1.7767 \mathrm{kgm}^{2}$

In order to determine linear velocity of the conveyor belt and the bottles, it is worth noting that as the drive pulley spins its circumferential distance in one revolution, the conveyor moves a linear distance equivalent to the circumference of the drive drum with a velocity $V_{b}$. The angular velocity and linear velocity are related as written in [5]. $V_{b}=\frac{1}{2} \omega(t) D_{m}$

$$
\omega(t)=\frac{2 V_{b}(t)}{D_{m}}
$$

$D_{m}$ is the diameter of driving pulley.

Substituting equations (34) and (35) in equations (12) to (15).

$$
\begin{aligned}
\frac{d i(t)}{d t} & =-\frac{R}{L} i(t)-\frac{2 K_{b}}{L D_{m}} V_{b}(t)+\frac{1}{L} V_{a p p} \\
\frac{2}{D_{m}} \frac{d V_{b}(t)}{d t} & =\frac{K_{m}}{J} i(t)-\frac{2 K_{b}}{J D_{m}} V_{b}(t) \\
& -\frac{\left(1.7607 \alpha_{m}+9.6825\right)}{J}
\end{aligned}
$$

Therefore,

$$
\frac{d V_{b}(t)}{d t}=\frac{K_{m}}{8 J} i(t)-\frac{K_{f}}{4 J D_{m}} V_{b}(t)-\frac{(9.6825)}{8 J}
$$

\subsection{Transfer Function Block Diagram}

Using differentials equations given in equations (40) and (42) and the Laplace transform of each equation gives:

$$
\begin{aligned}
s I(s)-i(0)=- & \frac{R}{L} I(s)-\frac{2 K_{b}}{L D_{m}} V_{b}(s) \\
& +\frac{1}{L} V_{a p p}(s) \quad(43) \\
s V_{b}(s)-V_{b}(0)= & \frac{K_{m}}{8 J} I(s)-\frac{K_{f}}{4 J D_{m}} V_{b}(s) \\
& -\frac{9.6825}{8 J s}(44)
\end{aligned}
$$

Let $J_{\text {tot }}^{-1}=\gamma_{1}$ and $L^{-1}=\gamma_{2}$, then equation 38 and 39 become

$\mathrm{SI}_{(\mathrm{s})}-\mathrm{i}(\mathrm{o})=-\gamma_{2}\left(\mathrm{RI}_{(\mathrm{s})}+\frac{2 K_{m}}{D_{m}} V_{b}(s) V_{a p p}(s)\right)$

And $\mathrm{sV}_{\mathrm{b}}(\mathrm{s})-\mathrm{V}_{\mathrm{b}}(0)=\gamma_{1}\left(\frac{K_{m}}{8} I_{(s)}-\frac{K f}{4 D_{m}} V_{b(s)}-\frac{9.6825}{8 s}\right)$

Considering steady state, the initial conditions equal to zero and all the variables becomes some change around a reference state, and the equations can be expressed as follows:

$$
\begin{gathered}
I(s)=\frac{-2 K_{b} V_{b}+D_{m} V_{a p p}(s)}{D_{m}(L s+R)} \\
V_{b}(s)=\frac{K_{m} D_{m} I(s)-10 D_{m} / s}{\left(8 J D_{m} s+2 K_{f}\right)}
\end{gathered}
$$

The equations above can be represented in a block diagram for the motor-conveyor system. Block diagram representation of equations (45) and (46) is in Figure 3.

If the response of interest is the linear velocity of the conveyor belt, the response $\mathrm{I}(\mathrm{s})$ is eventually eliminated when equation (45) is substituted in 
equation (46), and the resulting block diagram is Figure 4.

The closed-loop transfer function of the system is written as:

$$
\begin{aligned}
& G(s) \\
& =\frac{G_{1}(s) G_{2}(s) G_{3}(s)}{1+G_{1}(s) G_{2}(s) G_{3}(s) H(s)}
\end{aligned}
$$

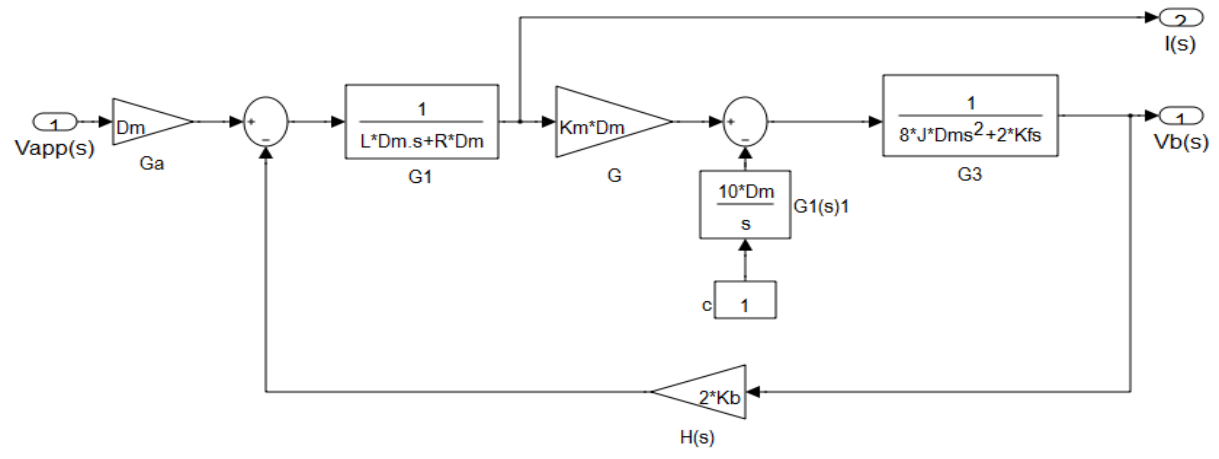

Figure 3: Block diagram representation of DC Motor and Belt Conveyor system

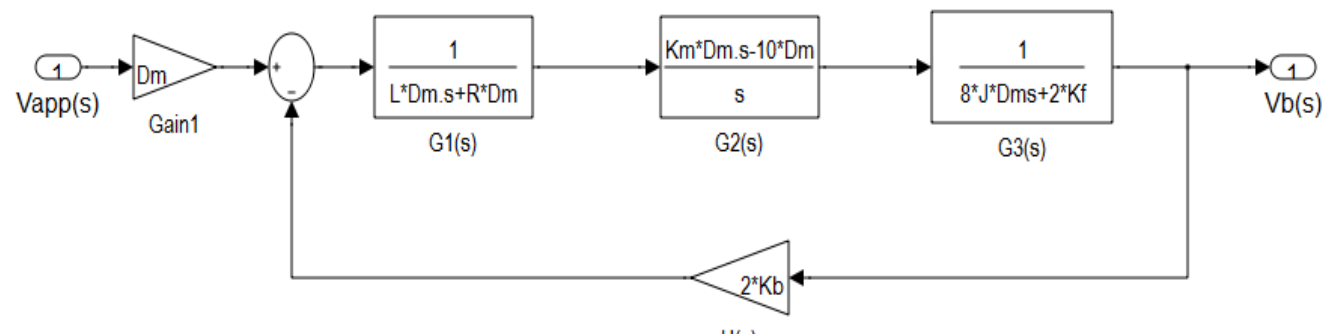

$\mathrm{H}(\mathrm{s})$

Figure 4: Resulting block diagram representation of DC Motor and Belt Conveyor system

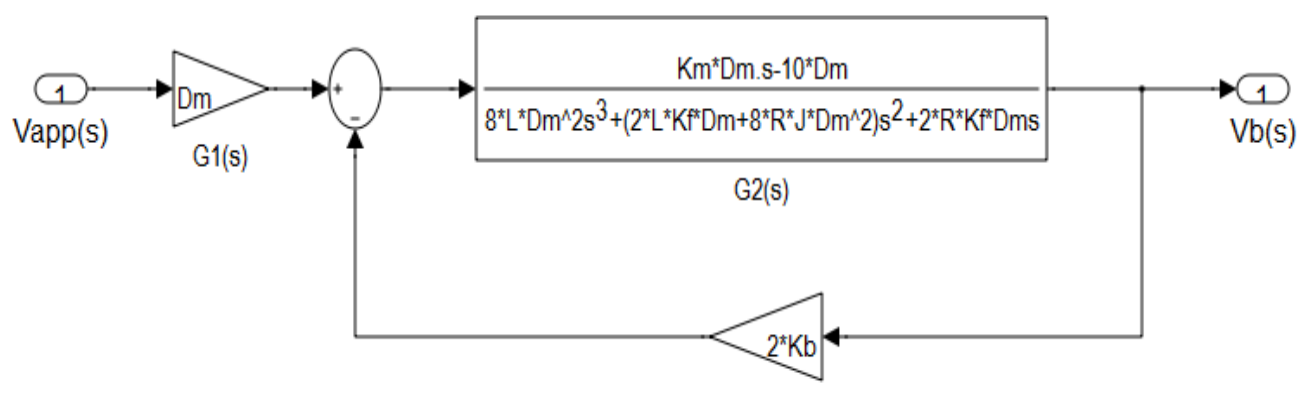

$\mathrm{H}(\mathrm{s})$

Figure 5: Final block diagram representation of DC Motor and Belt Conveyor system

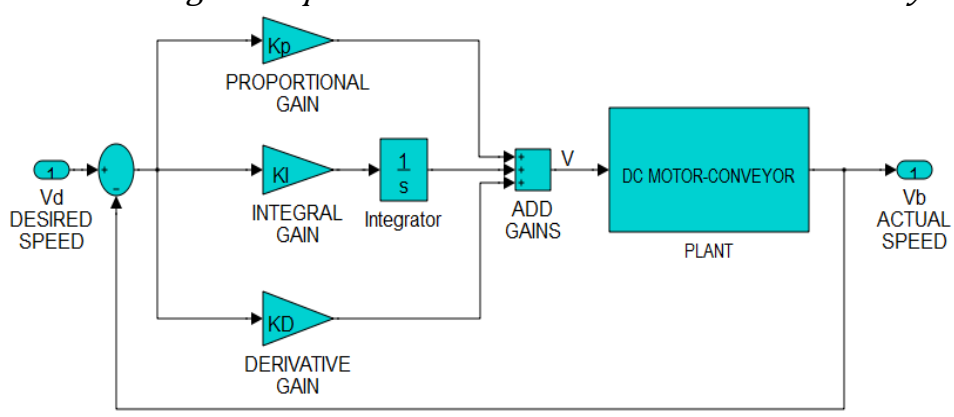

Figure 6: PID Controller Architecture 
Therefore, the overall transfer function for DC motor and conveyor system is written as

$$
\frac{V_{b}(s)}{V_{a p p}(s)}=\frac{\left[\left(K_{m} s-10\right)\right] / 8 L J}{s^{3}+\left[\left(2 L K_{f}+8 R J D_{m}\right) / 8 L J D_{m}\right] s^{2}+2\left[\left(R K_{f}+K_{b} K_{m} D_{m}\right) / 8 L J D_{m}\right] s-5 K_{b} / 2 L J}
$$

Applying the DC motor and belt conveyor parameters in Appendix A and Appendix B, the transfer function becomes

$$
\frac{V_{b}(s)}{V_{a p p}(s)}=\frac{0.1181 s-41.74}{s^{3}+29.63 s^{2}+1.217 s-2.362}
$$

\subsection{PID Controller Design}

PID control action is mathematically represented by the equation

$$
V=K_{p} E+K_{I} \int_{0}^{t} E d t+K_{D} \frac{d E}{d t}
$$

In (50), $K_{p}$ is proportional gain, $E$ is the error, $K_{I}$ is the Integral gain, $K_{D}$ is the derivative gain and $t$ is the time in seconds. Block diagram for equation (50) is illustrated in Figure 6. Applying Laplace Transform methods to equation (50), we have:

$$
\frac{V(s)}{E(s)}=K_{p}+\frac{K_{I}}{s}+K_{D} s
$$

A lag filter is introduced into the block diagram of Figure 6 to filter the derivative action of the PID compensator, and thus, equation (51) yields:

$$
\frac{V(s)}{E(s)}=K_{p}+\frac{K_{I}}{s}+K_{D}\left(\frac{N s}{s+N}\right)
$$

In (52), $N$ is the filter coefficient which sets the location of the pole of the derivative filter. Since a filter has been inserted as part of the PID architecture [18], it could now be termed PID with N-order filter on the derivative term (PID) [13]. Auto-tuning technique was used to tune the PID controller in order to achieve a good balance between performance and parameter variations [16].

\subsection{Formulation of Belt Conveyor Lines Speed Synchronisation Problem}

Next, it is pertinent to model the conveyor lines without synchronization before devising a control strategy for correcting the situation [17]. Data gathered from the industry confirmed that the effective length of the belt conveyor line is $30 \mathrm{~m}$. The bottle stack is expected to enter the conveyor line at distance zero and time less than 1 second. The Empty Bottle Inspection (EBI) unit is situated $5 \mathrm{~m}$ from the entrance to the conveyor line while the Full Bottle Inspection (FBI) machine is positioned $25 \mathrm{~m}$ from the same starting point. Figure 7 shows the arrangement. The control scenario will be formulated based on the following design requirements:

- The DC motor is placed on a $240 \mathrm{~V}, 50 \mathrm{~Hz}, \mathrm{DC}$ electric power source;
- Conveyor speed needs to be at a threshold of $0.85 \mathrm{~m} / \mathrm{s}$ for reduced momentum on the bottle stack during periods of pauses at EBI and FBI;

- Settling time for conveyor speed is between 0 and 1 second;

- There were six bottles in a single stack and was required to start moving in less than one second;

- The PID speed synchroniser was placed on a time function where the Empty Bottle Inspection (EBI) and Full Bottle Inspection (FBI) units discharged their duties every 3 seconds.

The designed controller is capable of regulating the velocity of the belt conveyor for different phases of the production processes.

\section{RESULTS AND DISCUSSION}

\subsection{Simulation Results of Dc Motor and Belt Conveyor System without Speed Synchroniser}

Figure 8 shows the results of the simulation for a period of 300 seconds which indicated that the armature current $I$ stabilizes at $4.5 \mathrm{~A}$ in less than 0.1 seconds. But it takes almost 150 seconds for the belt conveyor speed $V_{b}$ to stabilize at $6.5 \mathrm{~m} / \mathrm{s}$ and the bottle did not enter the conveyor line until about 20 seconds. From the response this model cannot be implemented in brewery industrial production line without a controller because of the high speed of the conveyor lines. The results are represented in Table 1 and Figure 8.

Table 1: PID Compensator parameters tuning results

\begin{tabular}{ll}
\hline Controller Performance and Robustness & Values \\
\hline Rise time (seconds) & 0.342 \\
Settling time (seconds) & 0.836 \\
Overshoot (\%) & 2.29 \\
Peak amplitude & 1.02 \\
Gain margin (dB) & $\underline{20.7 @ 20.3}$ \\
Bandwidth (rad/s) & 3.83 \\
Phase margin (degrees) & $45^{\circ}$ \\
Closed-Loop Stability & Stable \\
\hline
\end{tabular}

\subsection{Simulation Result of Maximum Attainable Speed}

Figure 9 shows the speed response of the system. The response indicated that the conveyor lines can attain 
a maximum velocity of $6.528 \mathrm{~m} / \mathrm{s}$ in about $150 \mathrm{sec}$. Having this precise value for the system speed gives a common set-point for setting the control design goals for tuning the PID speed synchroniser. The controller has been tuned to meet all our design requirements and the controller gains are presented in Table 2 .

Figure 10 shows the speed response by belt conveyor lines with PID speed synchronizer coupled to the model. It is evident from that the PID speed synchroniser has been able to maintain the speed of the conveyor lines at $6.528 \mathrm{~m} / \mathrm{s}$ but with a shorter response time of less than one second.

Table 2: PID Compensator tuning results

\begin{tabular}{lc}
\hline Controller Parameters & Tuned Gains Values \\
\hline Proportional Gain $K_{p}$ & 2497 \\
Integral Gain $K_{I}$ & 84 \\
Derivative Gain $K_{D}$ & 179 \\
Filter Coefficient $N$ & 14 \\
\hline
\end{tabular}

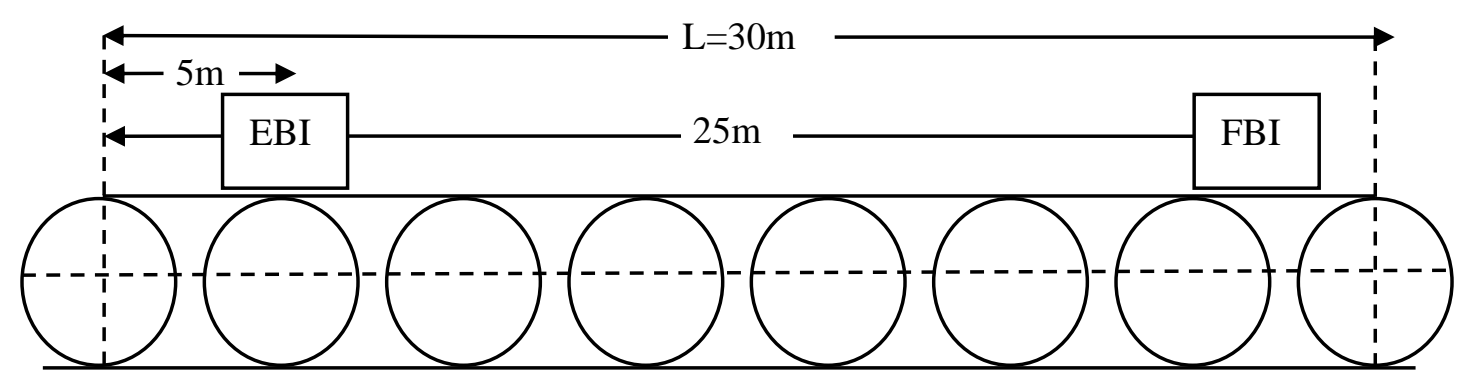

Figure 7: Schematic diagram of the belt conveyor lines

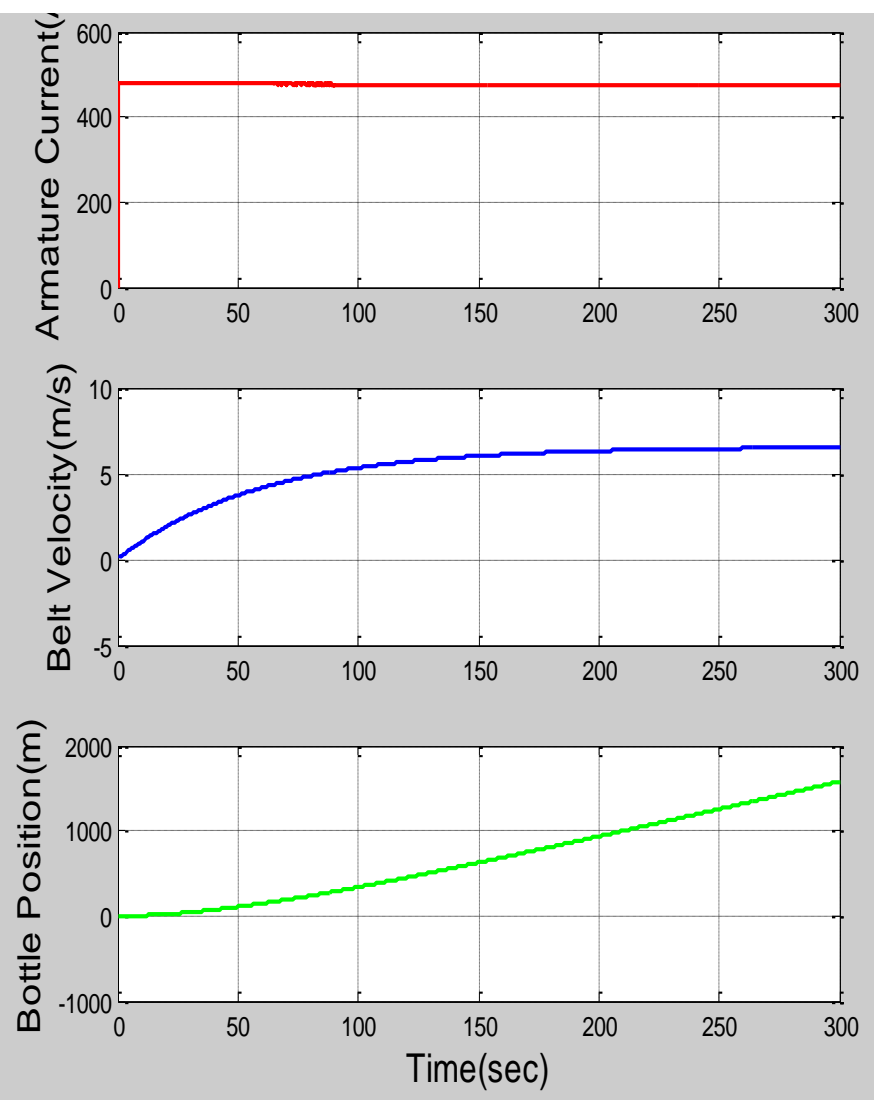

Figure 8: Simulated response of the DC Motor and Conveyor system

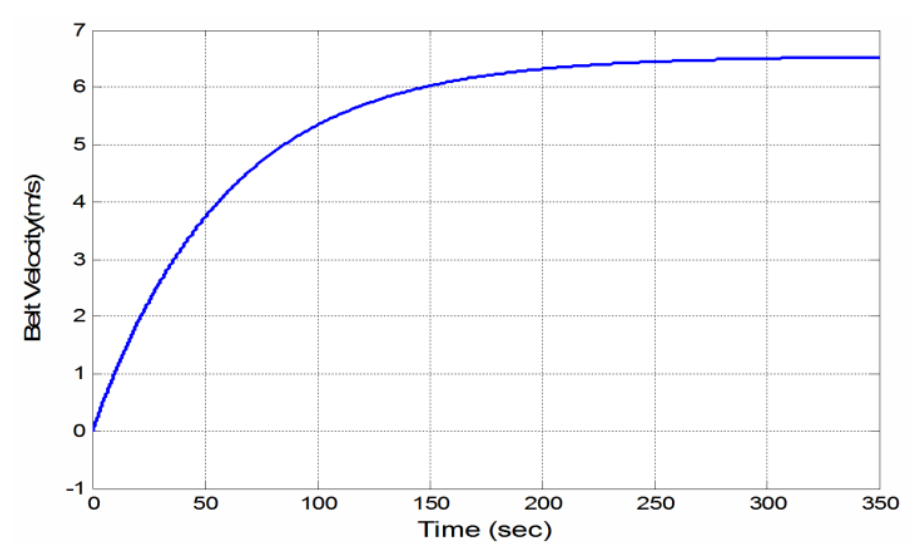

Figure 9: Maximum attainable speed by the belt conveyor

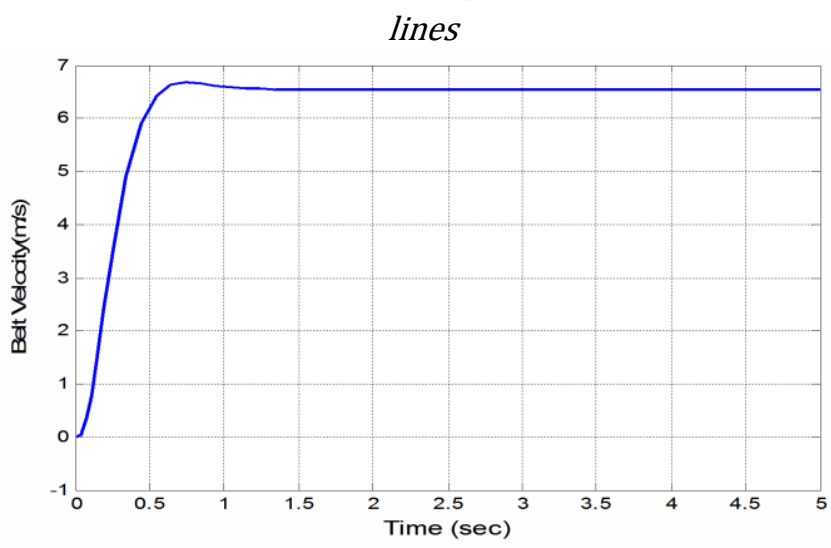

Figure 10: Speed response by the belt conveyor lines with PID speed synchroniser in the closed-loop 


\subsection{Simulation Results of Dc Motor and Belt Conveyor System with Speed Synchroniser}

The results from Figure 11 indicated that the system response improved reasonably when the PID speed synchroniser is coupled within the feedback loop; it took 0.75 seconds for the armature coil current to steady at $4.5 \mathrm{~A}$, the belt conveyor now used just 0.6 second to become stabilized at the same $6.5 \mathrm{~m} / \mathrm{s}$ and it lasted just 0.25 second before the bottle stack gained entrance into the conveyor line.

The PID controller has been tuned to meet all our design requirements and the comparison is presented in Table 3.

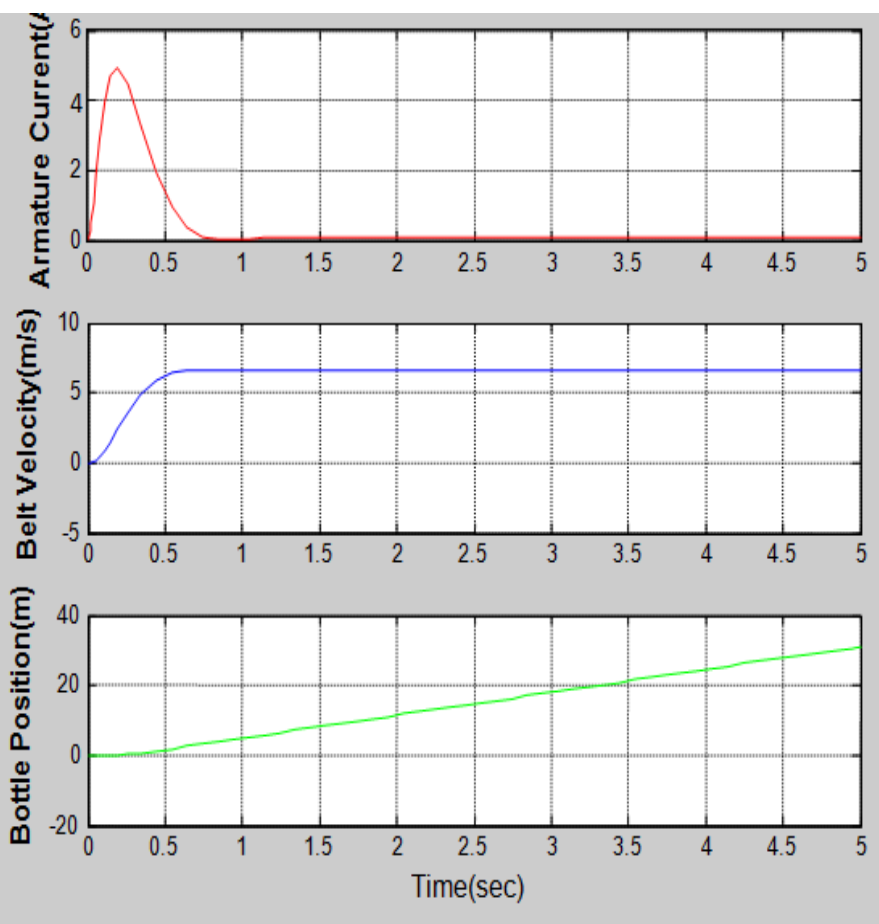

Figure 11: Simulated response of the DC Motor and Belt Conveyor with PID Compensator

Table 3: PID speed synchroniser performance

\begin{tabular}{llll}
\hline $\begin{array}{l}\text { Design } \\
\text { Requirements }\end{array}$ & Values & $\begin{array}{l}\text { Achieved Controller } \\
\text { Performance }\end{array}$ & Values \\
\hline Rise time (seconds) & $<0.5$ & Rise time (seconds) & 0.342 \\
Settling time & $<1.0$ & Settling time (seconds) & 0.836 \\
(seconds) & $<10.0$ & Overshoot $(\%)$ & 2.29 \\
Overshoot $(\%)$ & $<1.5$ & Peak & 1.02 \\
Peak & $>18$ & Gain margin (rad/s) & $20.7 \mathrm{~dB}$ \\
Gain margin (rad/s) & $>2.5$ & Bandwidth (rad/s) & 3.83 \\
Bandwidth (rad/s) & $>40^{\circ}$ & Phase margin & $45^{\circ}$ \\
Phase margin & & & \\
\hline
\end{tabular}

\section{CONCLUSION}

The mathematical model of a brewery's belt conveyor line, driven by a permanent magnet DC motor has been developed from basic physical laws. Having been faced with non-synchronisation of the production lines speed and processes, a Proportional Integral
Derivative(PID) controller with $\mathrm{N}$ order filter was designed from underlying control design theories and used as a speed synchroniser. The controller, whose design specifications were chosen to accommodate uncertainties in the system, was able to synchronise the speed of the conveyor lines with the speed of the empty bottle and full bottle inspection units.

\section{REFERENCES}

[1] Advitech Conveyor Noise Levels. Technical Report for Tyton Conveyors, 2003.

[2] Auguston, K. A.. Conveyor Systems and Noise Control. Modern Materials Handling, 1995.

[3] Cavallo.Using MATLAB, SIMULINK, and Control System Toolbox, Prentice Hall, Eaglewood Cliffs, N.J, 1996.

[4] CEMA Noise Considerations for Conveyor System Design and Application. CEMA Engineering Conference, pp. 11-16, 2003.

[5] CEMA Belt Book.Belt Tension, Power and Drive Engineering, 6 ${ }^{\text {th }}$ Edition, Chapter 6, 2011.

[6] Edward, C. L., Review of Variable Speed drive technology, Powertec Industrial Corporation, 2008.

[7] Field, K.. Engineers Turn Down Conveyor Noise. Design News, 2001.

[1] Kuo, B. C.. Automatic Control Systems, $7^{\text {th }}$ Edition. Englewood Cliffs, New Jersey, Prentice-Hall Inc., 1995.

[9] Lieberwirth, H.. Design of belt conveyors with horizontal curves, Bulk Solids Handling 14, pp. 283$285,1994$.

[10] Lodewijks, G.. The tow-dimensional behaviour of belt conveyors, Proceedings of the Beltcon 8 Conference, 24-26 October 1995, Pretoria, South Africa, 1995

[11] Lodewijks, G. Dynamics of Belt Systems, Ph.D dissertation, Delf University Technology, 2006.

[12] Lodewijks, G. Non-linear Dynamics of Belt Conveyor System, Bulk Solids Handling 17, pp. 57-67, 1997.

[13] Philips, L.. Analytical Bode Design of Controllers, IEEE Transactions of Education, pp. 43-44, 1985.

[14] Pulyer, Y. M.Electromagnetic Devices for Motion Control, Springer-Verlag, New York, 1992.

[15] Richard, C. D. and Robert, H. B., Modern control systems, $8^{\text {th }}$ Edition, Addison Wesley Longman, Inc., Menlo Park, Carlifonia, pp. 42-51, 1998.

[16] Saadat, H., Computational Aids in Control Systems Using MATLAB, McGraw-Hill, New York, 1993.

[17] Schlenker, B. R. Conveyors and Related Equipment, Moscow, Peace Publishers, 1979. 
[18] Sparke, C.. Conveyor Noise Assessment. Advitech 12, pp. 23-44, 2007.

\begin{tabular}{lll}
\multicolumn{3}{c}{ APPENDIX A: DC MOTOR PARAMETERS } \\
\hline Parameters & Values & Units \\
\hline Armature Resistance $(R)$ & 0.50 & $\Omega$ \\
Armature Coil Inductance $(L)$ & $1.69 \times 10^{-2}$ & $\mathrm{H}$ \\
Armature Torque Constant $\left(K_{m}\right)$ & $2.83 \times 10^{-2}$ & $\mathrm{Nm} / \mathrm{A}$ \\
Back emf constant $\left(\mathrm{K}_{\mathrm{b}}\right)$ & $2.83 \times 10^{-2}$ & $\mathrm{Vs} / \mathrm{rad}$ \\
Viscous Damping coefficient $\left(K_{f}\right)$ & $5.8 \times 10^{-2}$ & $\mathrm{Kgm}^{2} / \mathrm{s}$ \\
Motor Armature Inertia $\left(J_{R}\right)$ & $1.06 \times 10^{-2}$ & $\mathrm{Kgm}^{2}$ \\
\hline
\end{tabular}

APPENDIX B: BELT CONVEYOR PARAMETERS CEMA BELT BOOK (2011)

\begin{tabular}{lll}
\hline Parameters & Values & Units \\
\hline Conveyor Length $\left(L_{c}\right)$ & 30 & $\mathrm{M}$ \\
Conveyor width $(\mathrm{b})$ & 0.6 & $\mathrm{M}$ \\
Drive Drum Diameter $\left(D_{m}\right)$ & 0.2 & $\mathrm{M}$ \\
\hline
\end{tabular}

\begin{tabular}{lll}
\hline Parameters & Values & Units \\
\hline Driven Drum Diameter $\left(D_{1}\right)$ & 0.195 & $\mathrm{M}$ \\
Idler Diameter $\left(D_{i}\right)$ & 0.1 & $\mathrm{M}$ \\
Number of idlers $(\mathrm{n})$ & 15 & - \\
Idler spacing $(\mathrm{s})$ & 2 & $\mathrm{M}$ \\
Mass of bottle, empty/full $\left(M_{1}, \ldots\right)$ & 3.5 & $\mathrm{Kg}$ \\
Density of material (Aluminium) $(\rho)$ & 2702 & $\mathrm{Kg} / \mathrm{m}^{3}$ \\
Coefficient of friction between belt, & 0.35 & - \\
pulleys and idlers $(\mu)$ & 0.025 & $\mathrm{M}$ \\
Belt thickness $(t)$ & 0.2547 & $\mathrm{Kgm}{ }^{2}$ \\
Mass inertia of drive drum $\left(J_{m}\right)$ & 0.2302 & $\mathrm{Kgm}{ }^{2}$ \\
Mass inertia of driven drum $\left(J_{1}\right)$ & 0.0159 & $\mathrm{Kgm}{ }^{2}$ \\
Mass inertia of idler $\left(J_{r}\right)$ & 0.6 & $\mathrm{M}$ \\
Length of drums and idlers $(L)$ & $7.2(0.24 \mathrm{~kg} / \mathrm{m})$ & $\mathrm{Kg}$ \\
Mass of belt $\left(M_{\text {belt }}\right)$ & 480 & $\mathrm{Kg} / \mathrm{m}^{3}$ \\
Density of belt material $($ Rubber $)\left(\rho_{1}\right)$ & 6 & - \\
Number of bottle per stack $\left(n_{b}\right)$ & 6.81 & $\mathrm{~m} / \mathrm{s}^{2}$ \\
Acceleration due to gravity $(g)$ & 9.81 & \\
\hline
\end{tabular}

